\title{
Buckling strength of hydraulic cylinders - an engineering approach and finite element analysis
}

\author{
Evaldas Narvydas \\ Kaunas University of Technology, Studentu st. 56, LT-51424 Kaunas, Lithuania, E-mail: evaldas.narvydas@ktu.lt
}

cross $^{\text {ref }}$ http://dx.doi.org/10.5755/j01.mech.22.6.15374

\section{Introduction}

The buckling strength is one of the major requirements for hydraulic cylinders. Equation of buckling as an elastic instability of structures defined by Leonhard Euler in 1744 is still widely used in engineering practice. Well suitable for the linearly elastic slender structures, Euler's method demonstrated incapability to predict critical loads for structures of smaller slenderness with non-linear behaviour of material and/or imperfections of geometry and load. Various theoretical and experiment based empirical methods were developed to overcame deficiencies of Euler's method.

The article gives a short review of some recent problems considered in a critical load evaluation for the hydraulic actuators. There are also some engineering methods presented that are used in the industry of production of the hydraulic cylinders. However, the present day engineers are mastering the CAD/CAE applications and are willing to use it in the design and evaluation of the components. Therefore, the article is aiming to present an efficient finite element models for the critical buckling load calculation and compare it to the existing techniques used in practice of the design of hydraulic cylinders.

\section{Overview of some buckling strength evaluation methods of hydraulic cylinders}

Analytical research models

Recent developments in estimation of buckling load capacity for hydraulic cylinders pay attension to details often neglected by industry designers, such as a friction at suppors, imperfections coused by the misalignements at the junction of cylinder and road, wear of materials at the junction, pressure in the cylinder etc. Gamez-Montero at al $[1,2]$ developed a mathematical model acounting friction moments $\left(M_{1}, M_{2}\right)$ at supports and misalignment effects $\left(Y_{0 \mathrm{c}}\right)$, schematicaly presented in Fig. 1, b. Tomski and Uzny [3] presented mathematical model of hydraulic cylinder for analysis of stability and free vibrations taking in to acount the rotational rigidity $\left(C_{0}, C_{1},\right)$ at the pinned ends and translational rigidity $(C)$ at the rod end. The model also acounted the lengths of cylinder $\left(L_{11}\right)$, road $\left(L_{22}\right)$ and overlaping part $\left(L_{12}\right)$ (Fig. 1, c). Similar model was used by Uzny for elasticly fixed hydraulic cylinder, not considering the stifnes $C$ [4].

Numerical and analytical modeling of hydrocylinder taking in to account friction at suppors, misalignement in cylinder and rod junction and wear of sealing rings most recently was presented by $\mathrm{S}$. Baragetti, and F. Villa [5].

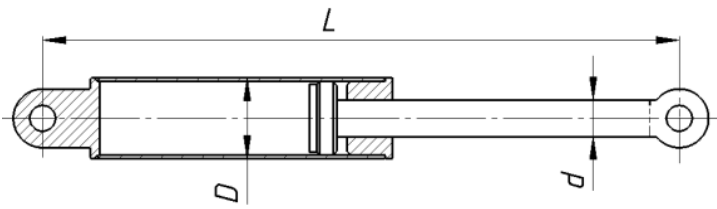

a

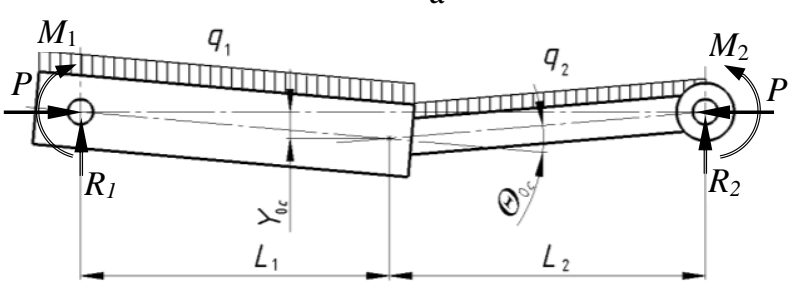

b

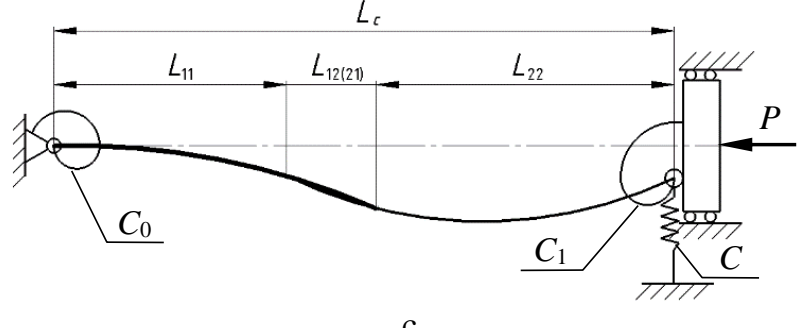

Fig. 1 Pin-ended hydraulic cylinder (a) and body schemes for mathematical modeling developed by GamezMontero at al [1, 2] (b) and Tomski at al [3] (c)

\section{Industry specifications}

To select a hydraulic cylinder with the required stroke length, customers are ofered to use a prepared charts or tables [6, 7]. However, some companies also provide methods, ilustrating how the buckling strength of the cylinder was calculated. E. g., technical specifications of hydraulic cyliders produced by Bosch Rexroth AG [7] include description of buckling (kinking) calculations. These calculations are based on Euler equation

$$
P_{c r}=\frac{\pi^{2} E I}{n L_{e}}, \text { if } \lambda>\lambda_{c r}
$$

and Tetmajer equation

$$
P_{c r}=\frac{d^{2} \pi(335-0.62 \lambda)}{4 n} \text {, if } \lambda \leq \lambda_{c r} \text {. }
$$

Constants 335 and 0.62 in Eq. (2) correspond to buckling test results presented by L. Tetmajer (1903) for steel columns having ultimate strength of $600 \mathrm{MPa}$. The other definitions in the above equations include: module of elasticity of the rod material $E$; geometrical moment of inertia for solid circular cross-section $I=\pi d^{4} / 64$, where $d$ is a 
diameter of piston rod; $L_{e}$ is an effective length depending on the type of mounting, $n$ is a safety factor, $\lambda$ is a slenderness ratio $\left(\lambda=4 L_{k} / d\right)$; critical slenderness $\lambda_{c r}=\pi \sqrt{\frac{E}{0.8 R_{e}}}$, here $R_{e}$ is a yield strength of the piston rod material. The safety factor $n=3.5$ is used. The admissible stroke length according to Bosch Rexroth also depend on the position of hydraulic cylinder instalation. Shorter strokes are alloved for horizontally installed actuators comparing to vertically installed. The allowed stroke lenghts are presented in a tabular form [7]. Therefore, it could be noted, that the above method takes in to the account only the diameter of piston rod. This approach is very simple and easy to use in engineering practice. The models, where the hydraulic cylinder is presented only by a piston rod cross-section, will be named as RD (rod diameter) models in the further text.

The DNV-GL class guideline for hydraulic cylinders [8] and DNV standard for certification of hydraulic cylinders [9] provide a buckling calculation method where the bucling load

$$
P_{E}=\frac{\pi^{2} E}{L Z}
$$

Here $L$ is a total length of the hydraulic cylinder between mountings in fully extracted position and $Z$ is a parameter dependent on moments of inertia of the cylinder tube $\left(I_{1}\right)$ and piston rod $\left(I_{2}\right)$, length of the cylinder tube part $\left(L_{1}\right)$ and length of the piston rod $\left(L_{1}\right)$ in a fully extracted position:

$$
Z=\frac{L_{1}}{I_{1}}+\frac{L_{2}}{I_{2}}+\left(\frac{1}{I_{2}}-\frac{1}{I_{1}}\right) \frac{L}{2 \pi} \sin \left(2 \pi \frac{L_{1}}{L}\right)
$$

The acceptance criteria (safety factor) is $P_{E} / P_{a} \geq 4$, where $P_{a}$ is an actual maximal load. Therefore, this method accounts the diameter and stroke length of the piston rod as well as the cross-section and length of the cylinder tube. The models of this kind will be caled as TRD (tube and rod diameter) models in this article.

\section{Finite element analysis procedures}

Two types of finite element buckling analysis were used in this reseach: a linear analysis based on eigenvalue solution and nonlinear analysis based on nonlinear static solution including material and geometry nonlinearity.

A linear buckling problem is formulated as an eigenvalue problem [10]:

$$
\left([K]+\lambda_{i}[S]\right)\left\{\psi_{i}\right\}=0
$$

where $[K]$ is a stiffness matrix $[S]$ is a stress stiffness matrix, $\lambda_{i}$ is an $i$-th eigenvalue used to multiply the loads that generate $[S]$ and $\psi_{i}$ is an $i$-th eigenvector of displacements. The initial $\left[S_{0}\right]$ is calculated solving static pre-buckling load $\left\{P_{0}\right\}$ problem. Then, the critical load $\left\{P_{c r}\right\}=\lambda_{i}\left\{P_{0}\right\}$. Therefore, $\lambda_{i}$ serves as a multiplication factor for the initial load to calculate the critical one.

A nonlinear buckling analysis was performed gradually increasig the axial force $P$. The critical load was

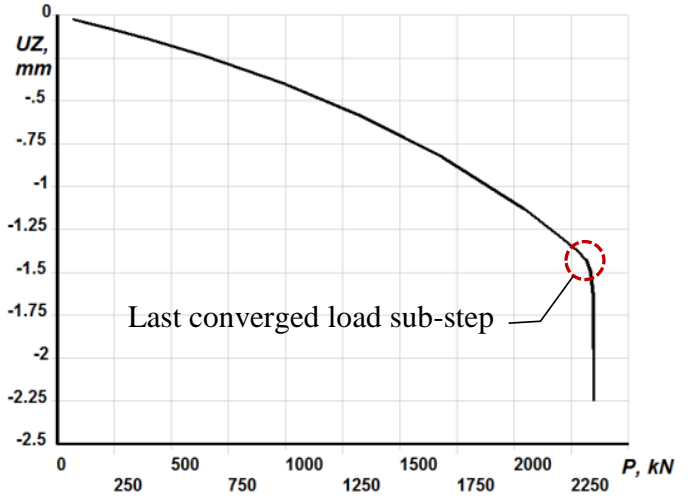

Fig. 2 Typical displacement $(U Z)-P$ curve showing solution convergence

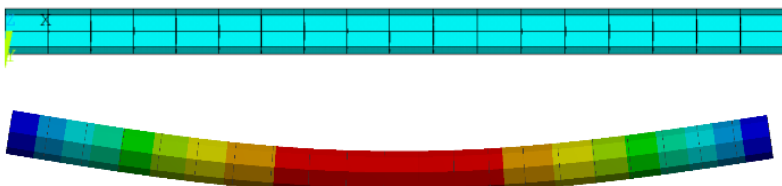

Fig. 3 Finite element mesh and 1-st buckling mode shape of RD model

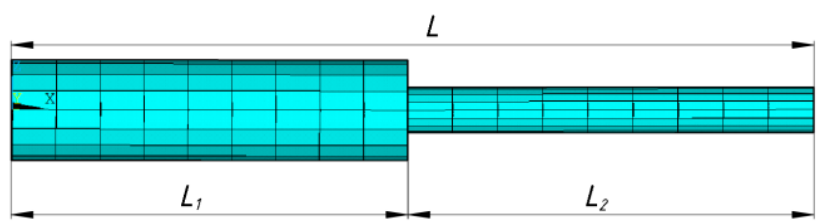

Fig. 4 Finite element mesh of TRD model

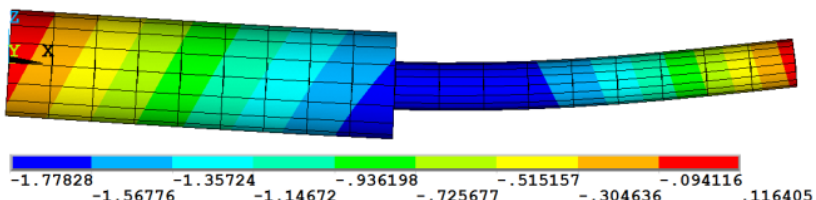

a

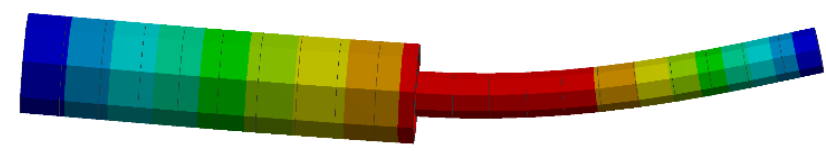

b

Fig. 5 Results of perpendicular displacements in the last converged load step of nonlinear analysis (a) and 1st buckling mode shape of the linear buckling analysis (b) of the TRD model

obtained by observing the solution convergence results and the force-displacement curve (Fig. 2). An initial imperfection needed to triger the buckling of the structure was created as a misalignamet of a tube and rod junction according to the scheme in Fig. $1, \mathrm{~b} ; Y_{0 c}=2 \mathrm{~mm}$. A constant gravity load aplied on the horizontally mounted hydraulic cylinder also contributed to the misalignement of structure.

\section{Initial data and assumptions}

For all analysis cases the ideal pin-ended suports were assumed, therefore, the friction in the supports, as well as stifness, were neglected $\left(M_{1}=M_{2}=0 ; C_{0}=C_{1}=0\right.$ and $C=\infty$ in the schemes Fig. 1, b and c). 
Material of the cylinder tube and rod was steel C45E; mechanical properties: $E=200000 \mathrm{MPa}$; Poison's ratio $v=0.3$; yield stress $R_{e}=369 \mathrm{MPa}$. Material finite element formulation included bilinear isotropic hardening rule with tangent modulus $E_{T}=1172 \mathrm{MPa}$, von Mises yield criteria and associated flow (plastic deformation) rule. Large displacement option (NLGEOM, ON [10]) was selected. Density of the materials: steel $\rho_{s}=7850 \mathrm{~kg} / \mathrm{m}^{3}$, oil inside the cylinder tube $\rho_{o}=879 \mathrm{~kg} / \mathrm{m}^{3}$ (used to account the selfweight under the gravity load with $g=9.81 \mathrm{~m} / \mathrm{s}^{2}$ ).

Geometry of the investigated structure: outside diameter of the cylinder tube $D=220 \mathrm{~mm}$, wall thickness 10 $\mathrm{mm}$; the rod had a solid circular cross-section with $d=100$ $\mathrm{mm}$. The buckling forces $P_{c r}$ and stresses $\sigma_{c r}$ were calculated for RD and TRD models in a range of slenderness ratio from 30 to 130 . To achieve this range of slenderness ratio, the overall length of the hydraulic cylinder $L$ was from 710 to $3245 \mathrm{~mm}$. The length of the tube $L_{1}$ for the TRD model was in a range from 350 to $1600 \mathrm{~mm}$ and the ratio $L_{1} / L_{2}$ was kept constant $(0.9726)$ i. e. the range of the rod length $L_{2}$ was from 360 to $1645 \mathrm{~mm}$.

For the linear finite element analysis, the RD and TRD models were created (Fig. 3 - Fig. 5). BEAM189 element type of the ANSYS software was selected for the piston rod and PIPE289 element type for the cylinder tube. The nonlinear analysis was performed only for the TRD models.

\section{Results and discussion}

The buckling stresses $\sigma_{c r}=P_{c r} / A_{2}$ for the investigated range of slenderness ratio are presented in Fig. 6. Here a cross-section area of the $\operatorname{rod} A_{2}=\pi d^{2} / 4$. Euler Eq. (1) and linear eigenvalue solution by finite elements for the RD model demonstrated the coincident results (curve 1) as expected. The critical slenderness ratio according to Bosch Rexroth [7] approach for the investigated actuator was $\lambda_{c r}=82$, therefore, for smaler slendernes ratio the Tetmajer Eq. (2) was employed. Curve 2 shows the results of Eq. (2) for the RD model.

The buckling stresses of the finite element linear analysis of the TRD model are presented by the curve 3. For this curve the effective slenderness ratio was calculated using Eq. (6). This equation for the overall effective slenderness ratio of two-staged column was derived by Sugiyama and Ohtomo [11] (later presented in English in [12])

$$
\lambda=\pi \sqrt{\frac{E}{P_{c r}}}\left(\sqrt{A_{1}} \frac{I_{1}}{L}+\sqrt{A_{2}} \frac{I_{2}}{L}\right)
$$

Here $A_{1}$ is an area of cross-section of the cylinder tube. To calculate $\lambda$, the buckling force $P_{c r}$ was extracted from the TRD linear finite element analysis results.

The nonlinear finite element analysis results of the TRD model are shown by square dots and noted by number 4. These results are presented addressing the slenderness ratio of Eq. (6). Although the model included the gravity load, three cases were calculated not considering this load ( $\mathrm{x}$ dots and number 4') for comparison. No significant influence of the self-weight on the buckling stress was noticed.

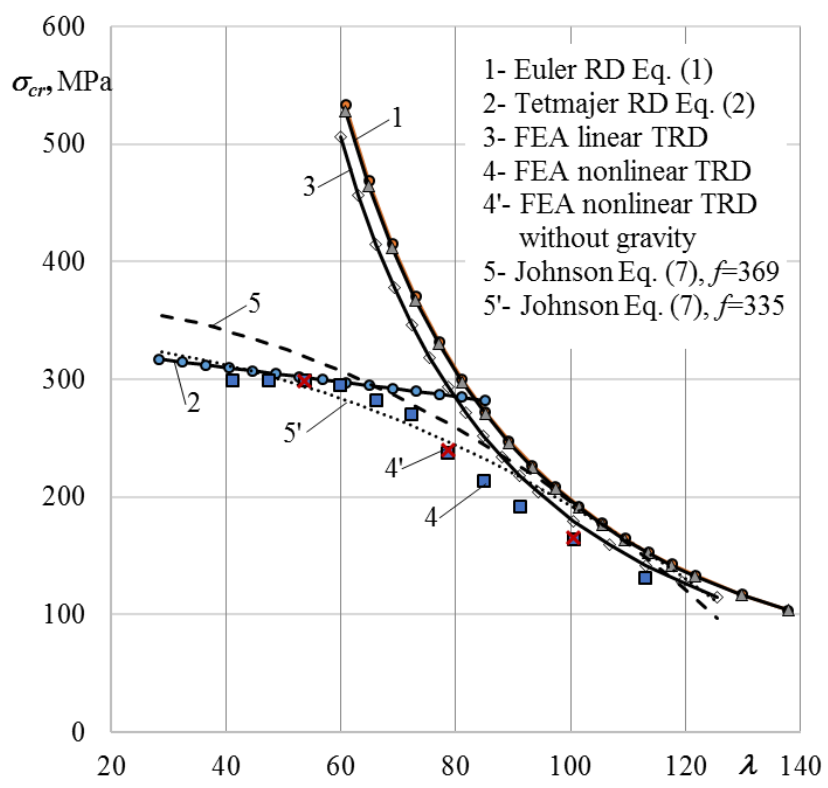

Fig. 6 Results of critical buckling stresses $\sigma_{c r}$ for different slenderness ratios $\lambda$ of RD and TRD models

The other popular way to calculate buckling stresses in a range of small slenderness ratios is a formula proposed by J. B. Johnson which can be written in a form:

$$
\sigma_{c r}=f\left(1-\frac{f \lambda^{2}}{4 \pi^{2} E}\right)
$$

Here $f$ usually is assumed equal to materials compressive yield stress. The dashed curve 5 (Fig. 6) was calculated by Eq. (7) assuming $f=R_{e}=369 \mathrm{MPa}$. However, a better fit to the nonlinear finite element analysis results was obtained, when $f$ was assumed equal to the same empirical coefficient 335 as in Tetmajers Eq. (2). These results are presented by a doted curve 5 '.

Buckling stress results presented in Fig. 6 show that the simple engineering method employing Eqs. (1) and

Table 1

Buckling stress comparison

\begin{tabular}{|l|l|l|l|l|l|}
\hline $\begin{array}{l}\text { Slender- } \\
\text { ness ra- } \\
\text { tio } \lambda\end{array}$ & $\begin{array}{l}\text { Euler } \\
\text { Eq. (1) }\end{array}$ & $\begin{array}{l}\text { Tetmaj } \\
\text { er Eq. } \\
(2)\end{array}$ & $\begin{array}{l}\text { FEA } \\
\text { Linear } \\
\text { TRD }\end{array}$ & $\begin{array}{l}\text { FEA } \\
\text { nonlin- } \\
\text { ear } \\
\text { TRD }\end{array}$ & $\begin{array}{l}\text { Johnson } \\
\text { Eq. (7) } \\
\text { MP3 } \\
\text { MPa }\end{array}$ \\
\cline { 2 - 6 } & \multicolumn{5}{|c|}{ Buckling stress $\sigma_{c r}$, MPa } \\
\hline 113 & 153 & - & 142 & 131 & - \\
\hline 101 & 192 & - & 180 & 165 & - \\
\hline 91 & 227 & - & 217 & 191 & 217 \\
\hline 85 & 272 & - & 251 & 213 & 233 \\
\hline 79 & - & 286 & - & 237 & 247 \\
\hline 72 & - & 290 & - & 271 & 261 \\
\hline 66 & - & 293 & - & 283 & 294 \\
\hline 60 & - & 297 & - & 295 & 284 \\
\hline & Difference comparing to FEA nonlinear TRD $4, \%$ \\
\hline 113 & 17 & - & 8.4 & 0 & - \\
\hline 101 & 16 & - & 9.1 & 0 & - \\
\hline 91 & 19 & - & 13 & 0 & 14 \\
\hline 85 & 29 & - & 17 & 0 & 9.4 \\
\hline 79 & - & 21 & - & 0 & 4.2 \\
\hline 72 & - & 7 & - & 0 & 3.7 \\
\hline 66 & - & 3.5 & - & 0 & 3.9 \\
\hline 60 & - & 0.7 & - & 0 & 3.7 \\
\hline
\end{tabular}


(2) (together with the safety factor 3.5) is reasonable. However, there is a critical range of slenderness ratio between 60 and 100 where the mentioned results have a large deviation from the nonlinear finite element analysis results. The maximum difference at $\lambda=85$ was $29 \%$ (see Table 1 for the other results in the mentioned range).

\section{Conclusions}

The BEAM type finite element models were proposed for the hydraulic cylinder buckling force and stress calculation.

The TRD model for nonlinear buckling analysis allows to capture the realistic buckling behaviour at the most critical range of slenderness ratio $(80 \ldots 90$ for the investigated structure) where the other methods give an error from 9 to $29 \%$. This model also demonstrated that the self-weight of the structure had a negligible effect on critical buckling load. The model consisted of 18 finite elements (Fig. 4) and computational time was within a few minutes, event if detail procedures were employed for searching of convergence.

The linear analysis of TRD model, based on eigenvalue solution, together with the slenderness correction by Eq. (6) iproved the results of Eulers Eq. (1) for RD model by $6 \ldots 9 \%$ and is proposed to use for the hydraulic cylinders when $\lambda>90$.

\section{Acknowledgement}

The author would like to acknowledge a business consultant of METEKA Mr. Algirdas Vigelis for his sugestions on industrial applications of design and buckling strength evaluation of hydraulic cylinders.

\section{References}

1. Gamez-Montero, P.J.; Salazar, E.; Castilla, R.; Freire, J.; Khamashta, M.; Codina, E. 2009. Misalignment effects on the load capacity of a hydraulic cylinder, International Journal of Mechanical Sciences 51: $105-113$. http://dx.doi.org/10.1016/j.ijmecsci.2009.01.001.

2. Gamez-Montero, P.J.; Salazar, E.; Castilla, R.; Freire, J.; Khamashta, M.; Codina, E. 2009. Friction effects on the load capacity of a column and a hydraulic cylinder, International Journal of Mechanical Sciences 51: 145-151. http://dx.doi.org/10.1016/j.ijmecsci.2008.12.007.

3. Tomski, L.; Uzny, S. 2011. A hydraulic cylinder subjected to Euler's load in aspect of the stability and free vibrations taking into account discrete elastic elements, Archives of civil and mechanical engineering 11, 3: 769785. http://dx.doi.org/10.1016/S1644-9665(12)60115-0.

4. Uzny, S. 2009. Free vibrations and stability of hydraulic cylinder fixed elastically on both ends. Proc. Appl. Math. Mech. 9: 303-304. http://dx.doi.org/10.1002/pamm.200910125.

5. Baragetti, S. and Villa, F. 2016. Effects of Geometrical Clearances, Supports Friction, and Wear Rings on Hydraulic Actuators Bending Behavior. Mathematical Problems in Engineering: 1-17. http://dx.doi.org/10.1155/2016/3781397.
6. APH Hydraulic Engineering Ltd [online]. C10 Industrial Cylinder Catalogue, Part 1. General information. [accessed 1 June, 2016]. Available from Internet: http://www.aph.co.uk/files/2013/6128/7565/general.pdf

7. Bosch Rexroth AG. [online]. Hydraulic cylinders. Mill type. RE 17332/01.16 [accessed 1 June, 2016]. Available from Internet:

https://md.boschrexroth.com/mod-

ules/BRMV2PDFDownload-

internet.dll/re17332_2016-

01.pdf?db=brmv2\&lvid $=1193069 \&$ mvid $=12454 \&$ clid $=$ 20\&sid=728BE37CFD9E918F5DC93241334B2F31.bo rex-tc\&sch=M\&id=12454,20,1193069.

8. DNV GL [online]. 2015. CLASS GUIDELINE DNVGL-CG-0194. Hydraulic cylinders. 19 p. [accessed 1 June, 2016]. Available from Internet: https://rules.dnvgl.com/docs/pdf/DNVGL/CG/201512/DNVGL-CG-0194.pdf.

9. DET NORSKE VERITAS. 2009. HYDRAULIC CYLINDERS. STANDARD FOR CERTIFICATION. No. 2.9. Type Approval Programme No. 5-778.93. 9 p. [also online, accessed 1 June, 2016]. Available from Internet:

https://rules.dnvgl.com/docs/pdf/DNV/tap/200910/TAP5-778-93.pdf.

10. ANSYS 16.2 Help System. 2015. Mechanical APDL Theory Reference. SAS IP, Inc.

11. Sugiyama, Y.; Ohtomo, T. 1995. Effective Slenderness Ratio for Long Columns Having Different Cross Sections. Transactions of the Japan Society of Mechanical Engineers Series A Vol. 61 No. 587: 1647-1650 (in Japanese). http://dx.doi.org/10.1299/kikaia.61.1647.

12. Sugiyama, Y.; Ohtomo, T. 1996. Buckling Load and Slenderness Ratio of Columns Having Piece-Wise Constant Cross Sections. Bulletin of Osaka Prefecture University. Series. A, Engineering and natural sciences 45(2): 111-117.

Evaldas Narvydas

\section{BUCKLING STRENGTH OF HYDRAULIC CYLINDERS - AN ENGINEERING APPROACH AND FINITE ELEMENT ANALYSIS}

S u m m a r y

Buckling strength is very important parameter for the compression load crying capacity of the hydraulic cylinders. The complexity of the determination of this parameter appears if the assembly of the hydraulic cylinder is detailed taking in to account: the cylinder, the piston rod, the joint between these parts and the pressure in the cylinder. The aim of the presented research is to evaluate some simplified engineering approaches used in the industrial design of the hydraulic cylinders and to suggest an efficient models applicable to use with the CAE software.

Keywords: buckling strength, hydraulic cylinder, FEA.

Received June 23, 2016 Accepted November 25, 2016 